\title{
Understanding of Active and Passive Constructions in 7- to 10-Year-Old Russian-Speaking Children: Reliance on Inflections or Word Order
}

\author{
Tatiana V. Akhutina ${ }^{\text {ał}}$, Yana R. Panikratova a,c , Alexey A. Korneev ${ }^{\mathrm{a}}$, \\ Ekaterina Yu. Matveeva ${ }^{\mathrm{a}}$, Rosa M. Vlasova ${ }^{\mathrm{b}}$ \\ ${ }^{a}$ Lomonosov Moscow State University, Moscow, Russia \\ ${ }^{\mathrm{b}}$ University of North Carolina at Chapel Hill, USA \\ ${ }^{c}$ Mental Health Research Center, Moscow, Russia \\ *Corresponding author. E-mail: akhutina@mail.ru
}

Background. The background of the present study includes analysis of the understanding of active and passive grammatical constructions (GCs) in Russianspeaking aphasic patients and in children aged 3, 4 and 5 years (Akhutina, 1989; Akhutina, Velichkovskiy, \& Kempe, 1988). Data regarding the reorganization of the children's strategies are further compared to GC understanding in children speaking different languages, and their interpretations.

Objective. To analyze the variable mechanisms of understanding of reversible GCs in primary-school-age children, namely, to reveal individual differences in reliance on word order or case endings.

Design. Ninety-three first-graders, 93 second-graders, and 63 third-graders underwent a neuropsychological assessment and computer-based sentence-topicture test of their understanding of reversible GCs of active/passive voice with direct/reverse word order. The "productivity" of understanding GCs (percent of correct responses) was analyzed through cluster analysis.

Results. The cluster analysis divided the children into four clusters. Cluster 1 consisted of eight children with low productivity, who were excluded from further analysis. Cluster 2 was characterized by low productivity in passive direct constructions (Group 1); Cluster 3 comprised children who had low productivity in passive reverse sentences (Group 2). Cluster 4 included children with good understanding of all GCs (Group 3). Between-group differences in productivity and time of correct responses in GCs, as well as neuropsychological indexes, were revealed.

Conclusion. The results are consistent with the following hypotheses: (a) Group 1 relies on the rule "The first noun is the agent", whereas the other two groups use morphological marking; (b) Group 1 is the weakest neuropsychologically, and syntactic understanding processes involve a more diffuse activation of the brain in this group, compared to more successful children; (c) changes in response times from the first to the second grade are under the influence of cerebral changes induced by reading acquisition.
Keywords: neuropsychology, individual differences, comprehension, grammatical constructions, children 


\section{Introduction}

The present study has a considerable background, linked to researching the mechanisms of syntax production and comprehension in models of aphasia and language acquisition. In the 1970s, T.V. Akhutina was investigating syntactic deficits in patients with Broca's aphasia. In a longitudinal study of reverse development of syntactic aphasia symptoms, she revealed three variants of syntactic disorders, differing in severity. A telegraphic style, the most severe variant of agrammatism, was characterized by combining words according to the pragmatic principle: "Rain child tree", "Radio weather rain". After that, patients began to use the rule of word order, making self-corrections like "Dinner...bread...no...mother bread...", and generating contrast pairs: "I went neighbors, neighbors...went I". Then these patients began to use regular marking of a direct object with inflections or even prepositions (notably, earlier marking was random). In some patients, this was followed by overgeneralization of marking: "Mother washed in a boy". After this, the set of surface rules slowly increased.

Combined research into the understanding of reversible active as well as passive grammatical constructions (GCs) in patients with medium and mild agrammatism variants demonstrated clear differences in understanding these types of GCs (Akhutina, 1979, 1989). Let us dwell on the method and the materials of these studies, because they were used in later research, including the current study.

In a sentence-to-picture test, patients were shown two pictures and had to choose the one relevant to the sentence they had heard. GCs can be divided into four types (see Table 1).

Table 1

The syntactic constructions used in the test

\begin{tabular}{lccl}
\hline \multicolumn{1}{c}{ Type of sentence } & $\begin{array}{c}\text { Surface } \\
\text { structure }\end{array}$ & Roles order & \multicolumn{1}{c}{ Examples } \\
\hline $\begin{array}{l}\text { Active with direct word } \\
\text { order (AD) }\end{array}$ & SVO & $\begin{array}{c}\text { Agent- } \\
\text { Patient }\end{array}$ & $\begin{array}{l}\text { Anna spasla Pet'u (Accus. case) } \\
\text { Ann saved Pete }\end{array}$ \\
$\begin{array}{l}\text { Active with reverse word } \\
\text { order (AR) }\end{array}$ & OVS & $\begin{array}{c}\text { Patient- } \\
\text { Agent }\end{array}$ & $\begin{array}{l}\text { Pet'u (Accus. case) spasla Anna } \\
\text { Pete (Accus. case) saved Ann }\end{array}$ \\
$\begin{array}{l}\text { Passive with direct word } \\
\text { order (PD) }\end{array}$ & SVO & $\begin{array}{c}\text { Patient- } \\
\text { Agent }\end{array}$ & $\begin{array}{l}\text { Pet'a spasen Annoy (Instr. case) } \\
\text { Pete was saved by Ann }\end{array}$ \\
$\begin{array}{l}\text { Passive with reverse word } \\
\text { order (PR) }\end{array}$ & OVS & $\begin{array}{c}\text { Agent- } \\
\text { Patient }\end{array}$ & $\begin{array}{l}\text { Annoy (Instr. case) spasen Pet'a } \\
\text { Byn Ann was saved Pete }\end{array}$ \\
\hline
\end{tabular}

Note: $S=$ subject, $V=$ verb, $O=$ object.

Patients with the medium variant of agrammatism gave the right answers for active direct $(A D)$, active reverse (AR), passive direct (PD), and passive reverse (PR) in 92, 50, 32, and 79 percent of cases, respectively; patients with milder agrammatism responded accurately in $97,89,81$, and 63 percent of cases. This means that the patients who relied on word order in language production used the rule "The first noun is the agent" in comprehension as well (the agent is in the first place in 
$\mathrm{AD}$ and $\mathrm{PR}$ ). In contrast, the patients who had begun using inflections in language production considered inflections also.

Comparative research into GC understanding in patients with other aphasia types showed pronounced difficulties in patients with semantic aphasia. They gave the right answers in $88,78,54$, and 61 percent of cases for $\mathrm{AD}, \mathrm{AR}, \mathrm{PD}$, and PR respectively. A.R. Luria explained such problems by "the disturbances of internal 'quasi-spatial' synthesis" (Luria, 1973). A similar interpretation and discussion of contemporary data can be found in the study of Thothathiri, Kimberg, and Schwartz (2012).

Difficulties in GC understanding in patients with acoustic-mnestic aphasia depended on aphasia severity and oral or written presentation of sentences, which pointed to a dependency of GC understanding on the possibility of sentence perception and retention in memory. Therefore, this deficit was secondary, not directly linked to syntactic difficulties (Akhutina, 1989). Similar data were found by Dragoy et al. (2015) for the other type of GCs.

To compare the mechanisms of syntax acquisition in normal children and its disintegration in aphasia, we carried out a study of the understanding of GCs in children aged from 3 to 5 years (Akhutina, 1989; Akhutina, Velichkovskiy, \& Kempe, 1988; Kempe, 1985), with the same method.

The results were similar for 3- and 5-year-olds, namely the response productivity decreased from AD to PR: 78, 75, 42, 39 percent of correct answers in 3-year-old children and 100,81, 69, and 61 percent in 5-year-olds.

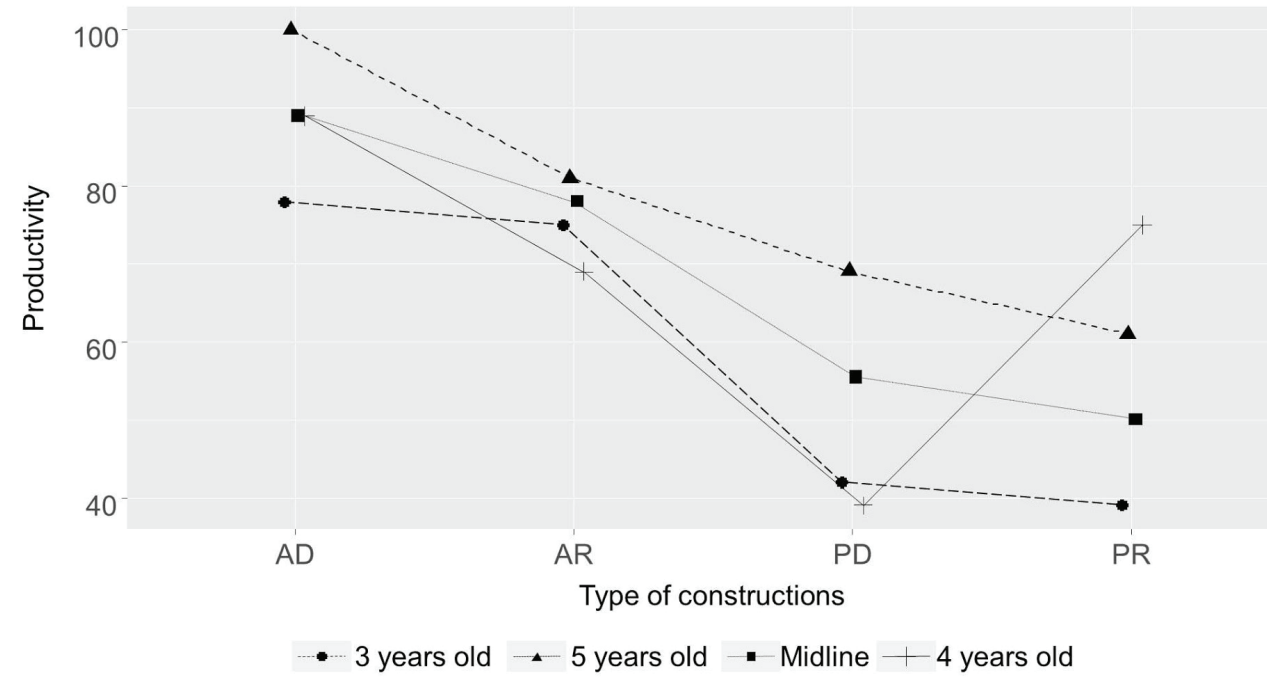

Figure. 1. Productivity (percent of correct responses) in GCs of four types in the 3-, 4- and 5 -year-olds.

A different picture was seen in 4-year-olds: $89,69,39$, and 75 percent of answers were correct. If we draw a midline between the results of 3 - and 5-year-olds and compare it to the results of 4-year-olds, we find that results in $\mathrm{AD}$ lie on this line; results in AR and particularly in PD are much worse than expected; and results in PR are much better than expected (see Fig.1). These children are relying on 
the rule "The first noun is the agent", which was interpreted as a sign of the prevailing semantic-syntactic strategy in understanding reversible constructions in the majority of 4-year-olds.

Notably, these data reflected not the common results for children of a particular age, but results of the leading groups (55, 73, and 88 percent in 3-, 4-, and 5-yearolds, respectively). Thus, we found that $73 \%$ of 4 -year-olds used the rule "The first noun is the agent", while $88 \%$ of 5 -year-olds used syntactic rules close to adult rules. We suggested that older children would rely on adult rules. However, this suggestion turned out to be wrong. A. Statnikov found that a significant number of firstgraders (7-year-olds), and especially children with speech disorders, understood reverse passive GCs better than direct GCs (Statnikov, 2015; Statnikov \& Akhutina, 2013).

We decided to verify these data through studying first-, second-, and thirdgraders. But before we turn to the methodology and results of our current study, let us discuss the results from study of other languages and their interpretation.

Studies of the understanding of active and passive GCs in children (matching a sentence to one of two pictures or manipulating with toys in act-out tests) have been ongoing for 50 years (Bever, 1970; Hakuta, 1982; MacWhinney \& Bates, 1989; MacWhinney, Pléh, \& Bates, 1985; Pléh, 1981; Slobin, 1966; Slobin \& Bever, 1982). One of the earliest studies summed up the results of understanding reversible GCs in the following way: "Two-year-olds understand transitive active sentences, threeyear-olds understand many passive sentences. Older children understand some sentences less well than younger children. This brief decrease in comprehension ability is due to the temporary overgeneralization of perceptual strategies which are drawn from the child's experience" (Bever, Mehler, \& Valian, 1968, p. 3). Bever (1970) described this strategy as follows: "Any Noun-Verb-Noun (NVN) sequence within a potential internal unit in the surface structure corresponds to 'actoraction-object'” (p. 22).

The decreased understanding of passive GCs in 4-year-olds was confirmed in many further studies of children acquiring different languages (Hakuta, 1982; MacWhinney \& Bates, 1989; MacWhinney, Pléh, \& Bates, 1985; Pléh, 1981; Slobin \& Bever, 1982). Bever et al. (1968) suggested the following interpretation of syntax mechanisms before, during and after overgeneralization: "(1) Dependence on basic perceptual and conceptual mechanisms, (2) extension of those basic mechanisms by generalization drawn from experience, and (3) the development of a broad conceptual base which mediates between the basic mechanisms and generalization" (p. 3).

Let us compare this hypothesis to the later point of view regarding the reorganization of representations in linguistic and cognitive domains within the model of representational redescription (RR model) by A. Karmiloff-Smith (1995). According to the RR model, development involves three recurrent phases. During the first phase, the child focuses on external data and achieves a relatively successful performance. In the second phase, the child is no longer focusing on the external data, and the internal representations begin to be changed. Finally, during the third phase, internal representations and external data are reconciled, and, regarding language, a new mapping is made between input and output representa- 
tions in order to restore correct usage. With the help of these reiterated phases, the child moves from one level of language acquisition to the next, and the format of the internal representations changes from an implicit level to explicit levels (E1, E2, E3). At the implicit level, information is encoded in a procedural form and new representations are independently stored. The representations are bracketed, so a procedure as a whole is available as data to other operators; however, its component parts are not, and hence no intra-domain or inter-domain information can yet be formed. Karmiloff-Smith notes that the implicit representations remain intact in the child's mind and can be called up later for particular goals that require speed and automaticity. The E1 representations are reduced descriptions that lose many details of the procedurally encoded information, and at the same time they are more cognitively flexible and can be manipulated and related to other re-described representations. However, they are not available to conscious access and the verbal report that is possible at levels E2 and E3. In the conclusion of her description of the RR model, Karmiloff-Smith notes that there are multiple levels at which the same knowledge is represented, and underlines that the notion of multiple encoding is important for our understanding of the workings of the human mind and brain.

Karmiloff-Smith's RR model corresponds to many findings in language acquisition research and aphasiology. We can mention first of all the usage-based theory of language acquisition, proposed by M. Tomasello (2009), according to which a child learns language from actual "usage events," i.e., from particular utterances in particular contexts, and builds up increasingly complex and abstract linguistic representations from these (Dittmar, Abbot-Smith, Lieven, \& Tomasello, 2008). This means that initial representations might be tied to the specific sentence-level properties of high-frequency events, including information about their prototypical semantic roles and animacy characteristics (Ambridge, Kidd, Rowland, \& Theakston, 2015; Buckle, Lieven, \& Theakston, 2017). We can also mention the dissociation of voluntary and involuntary speech/language processes in aphasia patients (Luria, 1970).

In terms of the RR model and the usage-based theory of language, it is easy to interpret the results of the language comprehension test in Russian-speaking 3- to 5-year-old children, described earlier. According to the RR model and the usagebased theory of language acquisition, at the first stage, 3-year-olds demonstrate procedures that were acquired independently of each other; the more frequently they were present in input, the better they are acquired. There are no general rules that combine all constructions; all of them are holistic gestalts ("bracketed representations"). Inner analysis of these procedures (the second phase, according to Karmiloff-Smith) leads to distinguishing the general, most regular pattern: A noun with the diffuse semantic-syntactic meaning of an agent takes the first place in an NVN sequence. The less reinforced the previous procedural knowledge, the greater the effect of the new rule (compare to Dittmar, Abbot-Smith, Lieven, \& Tomasello, 2014). We can see the biggest changes in understanding of the reverse passive (such GCs are very rare), then in the direct passive (they are rare constructions), then the reverse active (they are not so rare constructions). During the understanding of direct active constructions, old and new rules converge, and only 
the expected age-related changes are revealed (results of 4-year-olds constitute a mean between results of 3- and 5-year-olds). In general, a system of processing keeps both old and new rules, competing or converging with each other. The general consequence of stages in acquiring rules of understanding active and passive constructions can be observed in the comparison of our data to data of Germanspeaking children, because the German language also contains GCs with direct and reverse word orders. Two-year-olds correctly understood only sentences with both cues supporting each other - the prototypical form. Five-year-olds were able to use word order by itself, but not case markers. Only 7-year-olds behaved like adults by relying on case markers over word order when the two cues conflicted (Dittmar et al., 2008). The authors suggest that their findings demonstrate that prototypical instances of linguistic constructions with redundant grammatical marking play a special role in early acquisition (notably, that repeatability of prototypical constructions improves their primary acquisition on the level of procedural rules) and only later are children able to isolate and weigh individual grammatical cues appropriately (the possibility to isolate and compare the weights of grammatical cues occurs later, which coincides with Karmiloff-Smith's RR model). Prototypical constructions are characterized by an overlap of pragmatic, semantic, and syntactic attributes of the first noun (Bates, 1976; MacWhinney \& Bates, 1989). To conclude, an interaction between syntax and semantics in the first stages of language acquisition was reported on the behavioral level. There is also confirming evidence from neuroimaging.

Contemporary neuroimaging studies in neurolinguistics reveal bilateral localization of semantic processes and a unilateral localization of syntactic processes in adults (Bozic, Tyler, Ives, Randall, \& Marslen-Wilson, 2010; Wright, Stamatakis, \& Tyler, 2012), whereas in children, syntactic processes are localized bilaterally (Skeide \& Friederici, 2016). The latter authors demonstrated that "functional selectivity for sentence-level semantic information becomes neuro-anatomically separable from functional selectivity for sentence-level syntactical information between the ages of 7 and 9, and it is only after the age of 10 that BA44 (Brodmann's area) reaches its full specificity and ultimate efficiency in processing complex syntax" (p. 7).

The above-mentioned studies are aimed at general patterns of syntax development, but there are also studies of individual differences or distinct strategies in language acquisition. It is well known that this approach is one of the most productive for investigating mechanisms of language acquisition. Classical studies in ontolinguistics allowed researchers to distinguish two variants of language development: referential and expressive (Bates, Bretherton, \& Snyder, 1988; Nelson, 1973; Shore, 1995; see also Dobrova, 2009). Modern researchers are continuing to analyze individual variability in mechanisms of the development and functioning of language comprehension through new neuroimaging methods in an event-related potential (ERP) paradigm (Pakulak \& Neville, 2010; Prat \& Just, 2011; Yeatman, Ben-Shachar, Glover, \& Feldman, 2010). They discuss different factors such as working memory (Just \& Carpenter, 1992, and subsequent works) or education level (Dąbrowska, 2012). However, to the best of our knowledge, no one has discussed distinct strategies of understanding GCs and their mechanisms. 


\section{Method}

The aim of our study was to analyze the variability of mechanisms by which primary-school-age children understand reversible GCs, namely, to reveal individual differences in relying on word order or case endings, and to suggest possible interpretations of these mechanisms.

\section{Participants and procedure}

The children (93 first-graders, 93 second-graders, and 63 third-graders) underwent a neuropsychological assessment adapted for children (Akhutina et al., 2016), as well as a computer-based sentence-to-picture test of understanding reversible GCs: AD, AR, PD, and PR constructions. In this test, a child had to choose one of the two pictures, relevant to the heard sentence, by pressing a key (Akhutina, Korneev, \& Matveeva, 2017a; Statnikov \& Akhutina, 2013). Two indexes were used for further analysis: productivity (percent of correct answers) and time of correct responses.

\section{Data processing}

In order to divide the children into groups differing in their productivity of understanding the four types of GCs, $\mathrm{k}$-means clustering was used (via SPSS, version 22). Relying on the results of preliminary hierarchical clustering (between-groups linkage), we decided to extract four clusters. They differed in all four variables used for the clustering (productivity of understanding AD, AR, PD, and PR constructions) (ANOVA, $p<.001$, see Table 2 ). The number of maximum iterations was 10 .

Table 2

ANOVA in k-means clustering, demonstrating that four extracted clusters significantly differed in all four variables used for clustering.

\begin{tabular}{lllllll}
\hline & \multicolumn{5}{c}{ Cluster } & \multicolumn{2}{c}{ Error } & F & Sig. \\
\cline { 2 - 5 } & Mean square & df & Mean square & df & & \\
\hline AD & 0.678 & 3 & .021 & 245 & 32.994 & .000 \\
$\mathrm{AR}$ & 0.587 & 3 & .030 & 245 & 19.601 & .000 \\
$\mathrm{PD}$ & 2.524 & 3 & .021 & 245 & 123.063 & .000 \\
$\mathrm{PR}$ & 2.609 & 3 & .015 & 245 & 170.401 & .000 \\
\hline
\end{tabular}

Cluster 1 consisted of a small number of children with low productivity $(6,0$, and 2 children from the first, second, and third grades, respectively); they were excluded from further analysis. Cluster 2 included children with low productivity in understanding PD structures $(23,18$, and 12 children from the first, second, and third grades, respectively, hereinafter Group 1); Cluster 3 included children with poor understanding of PR structures $(27,22$, and 13 children from the first, second, and third grades, hereinafter Group 2); Cluster 4 included the most successful children with a good understanding of all GCs (37, 53, and 36 children 
from the first, second and third grades, hereinafter Group 3). See Table 3 for final cluster centers.

Table 3

Final cluster centers

\begin{tabular}{lcccc}
\hline & \multicolumn{5}{c}{ Clusters } \\
\cline { 2 - 5 } & $\mathbf{1}$ & $\mathbf{2}$ & $\mathbf{3}$ & $\mathbf{4}$ \\
\hline Productivity in AD & 0.37 & 0.88 & 0.86 & 0.89 \\
Productivity in AR & 0.53 & 0.62 & 0.77 & 0.81 \\
Productivity in PD & 0.6 & 0.45 & 0.81 & 0.89 \\
Productivity in PR & 0.25 & 0.73 & 0.52 & 0.89 \\
\hline
\end{tabular}

Neuropsychological indexes reflecting different components of higher mental functions were derived from the neuropsychological assessment. These indexes concerned (1) executive functions, (2) serial organization of movements, (3) processing of kinesthetic information, (4) auditory information, (5) visual information, and (6) visuospatial information. Furthermore, there were integral indexes of (7) left hemisphere and (8) right hemisphere functions, (9) functions of the first brain unit (regulation of activation level), as well as (10) a summary index of indexes 1-6. These indexes were calculated following the principle of "penalty points", with higher scores reflecting the "weakness" of the function, the sample mean equal to zero, and negative values reflecting the "strength" of the function. A more detailed description of the calculation of neuropsychological indexes can be found in Korneev and Akhutina (2016).

To examine the effects of group $(1,2,3)$ and grade $(1,2,3)$ on neuropsychological indexes, we carried out a two-way ANOVA (via R Studio). A distinct general linear model was calculated for each index (10 indexes in total), and p-values were Bonferroni-corrected for multiple comparisons.

\section{Results}

The distribution of children by Groups 1, 2, and 3 in the three grades was as follows: 26, 31, 43\% (grade 1); 19, 24, 57\% (grade 2); and 20, 21, 59\% (grade 3).

Analysis of response productivity by groups (see Fig. 2 and Table 1A in Appendix) demonstrated that the percentage of correct responses for Group 1 was $84-95 \%$ in $\mathrm{AD}, 71-75 \%$ in $\mathrm{PR}$, and $60-67 \%$ in $\mathrm{AR}$. The percentage of correct responses in PD for this group was close to random (43-50\%). The children in Group 2 were characterized by the greatest percentage of correct responses for AD (84$87 \%)$, lower percentages for PD and AR (77-91\% and 75-80\%, respectively), and a much lower percentage of correct responses for PR (47-57\%). Finally, Group 3 showed high productivity in all GCs (79-91\%). These data are in agreement with the hypothesis that Group 1 is under the influence of the rule "The first noun is the agent", whereas the other two groups rely on morphological aspects of the words in understanding GCs. 


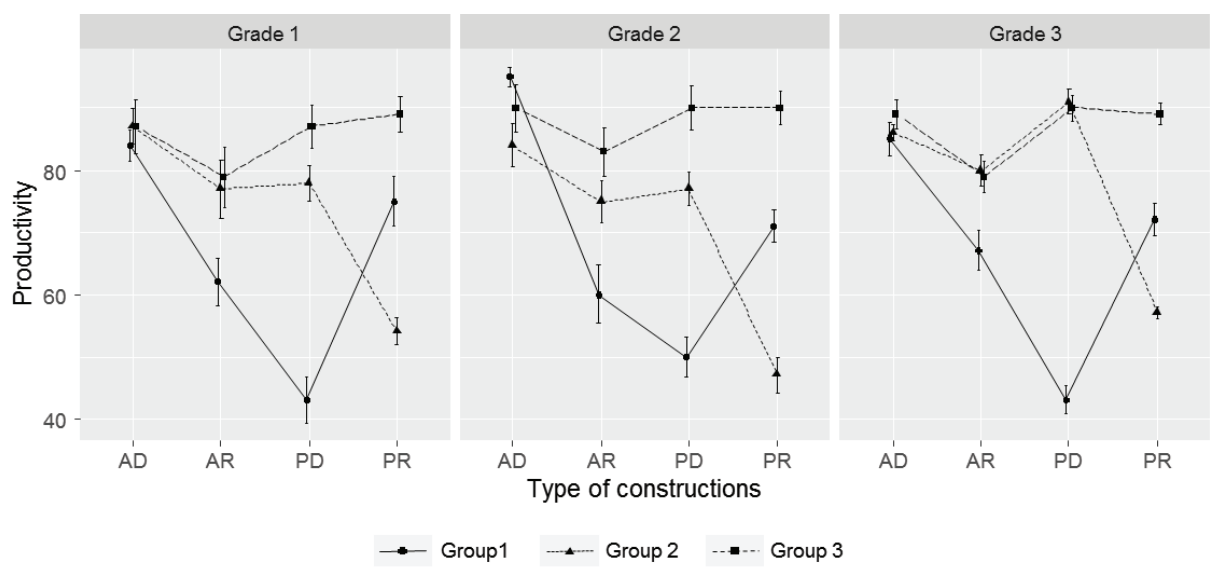

Figure 2. Productivity (means) for the three groups of children in grades 1-3.

Analysis of the time of correct responses by groups (see Fig. 3 and Table 1A in Appendix) showed that response time for $\mathrm{AD}$ was minimal for all groups in all grades. A minimal difference in response time between $\mathrm{AD}$ and the other GCs in the first grade was revealed between AD and PR in Group 1 (only $284 \mathrm{~ms}$ ). This result supports the hypothesis that these children used the strategy of relying on word order in understanding passive constructions. However, in the second and third grades, response time for PR increased, although productivity in PR stayed the same. We will discuss these findings below.

The time of correct responses in AR was similar to AD. AR constructions were in the first place after $\mathrm{AD}$ in most cases for Groups 2 and 3; in Group 1 they took second place after PR in the first grade and first place in grades $2-3$. An effortless understanding of AR constructions is an expected finding, because they are the next after $\mathrm{AD}$ in frequency of use and are linked to minimal changes in AD.
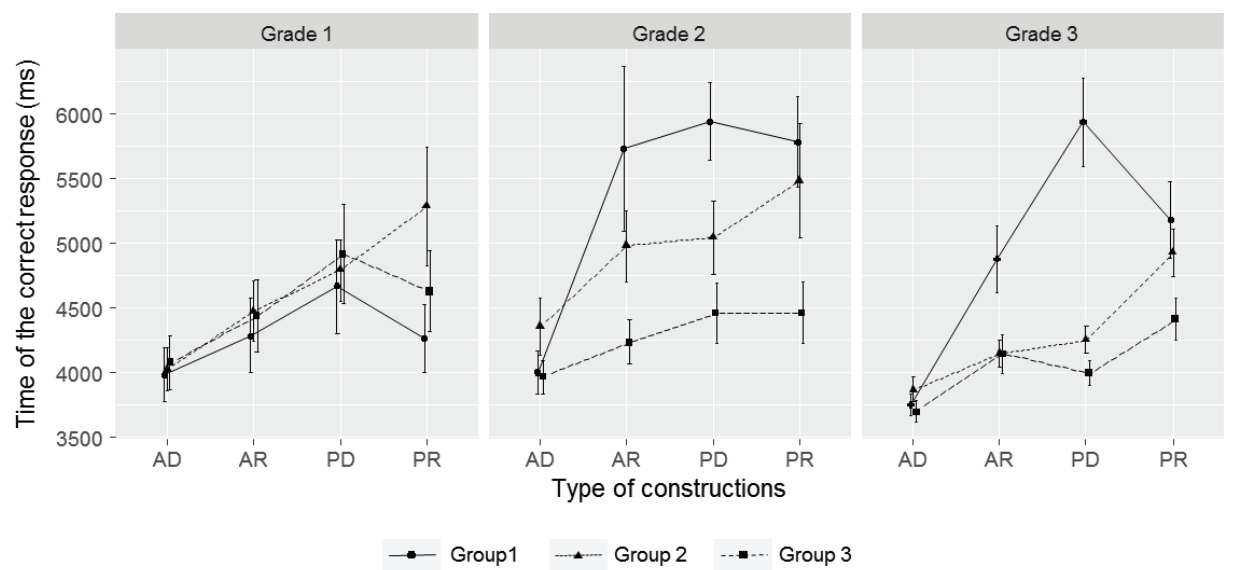

Figure 3. Time of the correct response (means) for the three groups of children in grades 1-3.

A maximal difference in response time between $\mathrm{AD}$ and the other GCs varied from one group to another. In all grades in Group 1, it was a difference between AD 
and PD; in Group 2, it was a difference between AD and PR. Group 3 differences in response times were slight, and the place of maximal difference varied from grade to grade.

Notably, Group 1 in the first grade was characterized by faster correct responses on average than the other two groups. However, the situation changed in the second and third grades: Group 3 became the fastest, while Groups 1 and 2 became much slower. This result is worth discussing too.

Table 4

Results of the two-way ANOVA, examining the difference between groups $(1,2,3)$ and grades $(1,2,3)$ in neuropsychological indexes. Bonferroni-corrected for multiple comparisons, and uncorrected p-values are given.

\begin{tabular}{|c|c|c|c|}
\hline $\begin{array}{l}\text { Neuropsychological } \\
\text { index }\end{array}$ & Group factor & Grade factor & $\begin{array}{l}\text { Interaction between } \\
\text { Group and Grade }\end{array}$ \\
\hline $\begin{array}{l}\text { Executive functions } \\
(3.1)\end{array}$ & $\begin{array}{l}F(2,219)=5.54 \\
p_{\text {uncorr }}=.004 \\
p_{\text {corr }}=.04^{\star}\end{array}$ & $\begin{array}{l}F(2,219)=5.43 \\
p_{\text {uncorr }}=.005 \\
p_{\text {corr }}=.05^{\star}\end{array}$ & $\begin{array}{l}F(4,219)=1.19 \\
p_{\text {uncorr }}=.32\end{array}$ \\
\hline $\begin{array}{l}\text { Serial organization } \\
\text { (3.2) }\end{array}$ & $\begin{array}{l}F(2,221)=7.9 \\
p_{\text {uncorr }}=.9\end{array}$ & $\begin{array}{l}F(2,221)=3.24 \\
p_{\text {uncorr }}=.04, p_{\text {corr }}=.4\end{array}$ & $\begin{array}{l}F(4,221)=0.77 \\
p_{\text {uncorr }}=.54\end{array}$ \\
\hline $\begin{array}{l}\text { Processing of } \\
\text { kinesthetic } \\
\text { information (2.1) }\end{array}$ & $\begin{array}{l}F(2,221)=0.09 \\
p_{\text {uncorr }}=.002 \\
p_{\text {corr }}=.02^{*}\end{array}$ & $\begin{array}{l}F(2,221)=6.27 \\
p_{\text {uncorr }}=.002 \\
p_{\text {corr }}=.02^{\star}\end{array}$ & $\begin{array}{l}F(4,221)=0.25 \\
p_{\text {uncorr }}=.9\end{array}$ \\
\hline $\begin{array}{l}\text { Processing of auditory } \\
\text { information }(2.2)\end{array}$ & $\begin{array}{l}F(2,218)=12.78 \\
p_{\text {uncorr }}=.000006 \\
p_{\text {corr }}=.00006^{*}\end{array}$ & $\begin{array}{l}F(2,218)=14.94 \\
p_{\text {uncorr }}=.0000008 \\
p_{\text {corr }}=.000008^{\star}\end{array}$ & $\begin{array}{l}F(4,218)=1.1 \\
p_{\text {uncorr }}=.36\end{array}$ \\
\hline $\begin{array}{l}\text { Processing of visual } \\
\text { information }(2.3)\end{array}$ & $\begin{array}{l}F(2,212)=11.67 \\
p_{\text {uncorr }}=.000015 \\
p_{\text {corr }}=.00015^{\star}\end{array}$ & $\begin{array}{l}F(2,212)=15.83 \\
p_{\text {uncorr }}=.0000004 \\
p_{\text {corr }}=.000004^{*}\end{array}$ & $\begin{array}{l}F(4,212)=2.24 \\
p_{\text {uncorr }}=.07\end{array}$ \\
\hline $\begin{array}{l}\text { Processing of } \\
\text { visuospatial } \\
\text { information (2.4) }\end{array}$ & $\begin{array}{l}F(2,217)=8.61 \\
p_{\text {uncorr }}=.00025 \\
p_{\text {corr }}=.0025^{\star}\end{array}$ & $\begin{array}{l}F(2,217)=7.55 \\
p_{\text {uncorr }}=.0007 \\
p_{\text {corr }}=.007^{\star}\end{array}$ & $\begin{array}{l}F(4,217)=0.23 \\
p_{\text {uncorr }}=.92\end{array}$ \\
\hline Left hemisphere & $\begin{array}{l}F(2,215)=10.59 \\
p_{\text {uncorr }}=.00004 \\
p_{\text {corr }}=.0004^{*}\end{array}$ & $\begin{array}{l}F(2,215)=10.36 \\
p_{\text {uncorr }}=.00005 \\
p_{\text {corr }}=.0005^{\star}\end{array}$ & $\begin{array}{l}F(4,215)=0.3 \\
p_{\text {uncorr }}=.87\end{array}$ \\
\hline Right hemisphere & $\begin{array}{l}F(2,214)=13.22 \\
p_{\text {uncorr }}=.000004 \\
p_{\text {corr }}=.00004^{\star}\end{array}$ & $\begin{array}{l}F(2,214)=5.45 \\
p_{\text {uncorr }}=.005 \\
p_{\text {corr }}=.05^{\star}\end{array}$ & $\begin{array}{l}F(4,214)=0.55 \\
p_{\text {uncorr }}=.7\end{array}$ \\
\hline $\begin{array}{l}\text { Regulation of activa- } \\
\text { tion (the first brain } \\
\text { unit) }\end{array}$ & $\begin{array}{l}F(2,215)=3.4 \\
p_{\text {uncorr }}=.03 \\
p_{\text {corr }}=0.3\end{array}$ & $\begin{array}{l}F(2,215)=8.87 \\
p_{\text {uncorr }}=.0002 \\
p_{\text {corr }}=.002^{\star}\end{array}$ & $\begin{array}{l}F(4,215)=0.6 \\
p_{\text {uncorr }}=.66\end{array}$ \\
\hline Summary index & $\begin{array}{l}F(2,200)=18.2, \\
p_{\text {uncorr }}=.00000005, \\
p_{\text {corr }}=.0000005^{\star}\end{array}$ & $\begin{array}{l}F(2,200)=27.67 \\
p_{\text {uncorr }}=.00000000002, \\
p_{\text {corr }}=.0000000002^{\star}\end{array}$ & $\begin{array}{l}F(4,200)=0.93 \\
p_{\text {uncorr }}=.44\end{array}$ \\
\hline
\end{tabular}

Note: Results with $p \leq .05$, corrected for multiple comparisons, are marked with * 
A two-way ANOVA examining the difference between groups $(1,2,3)$ and grades $(1,2,3)$ in neuropsychological indexes (see Table 4$)$ led to the conclusion that 8 of 10 indexes (except processing of kinesthetic information and regulation of activation) significantly differed between groups; 9 of 10 indexes (except serial organization) differed between grades.

Analysis of the neuropsychological assessments demonstrated that Group 1 was "the weakest", whereas Group 3 was "the strongest" (see Fig. 4, and Table 2A in Appendix).

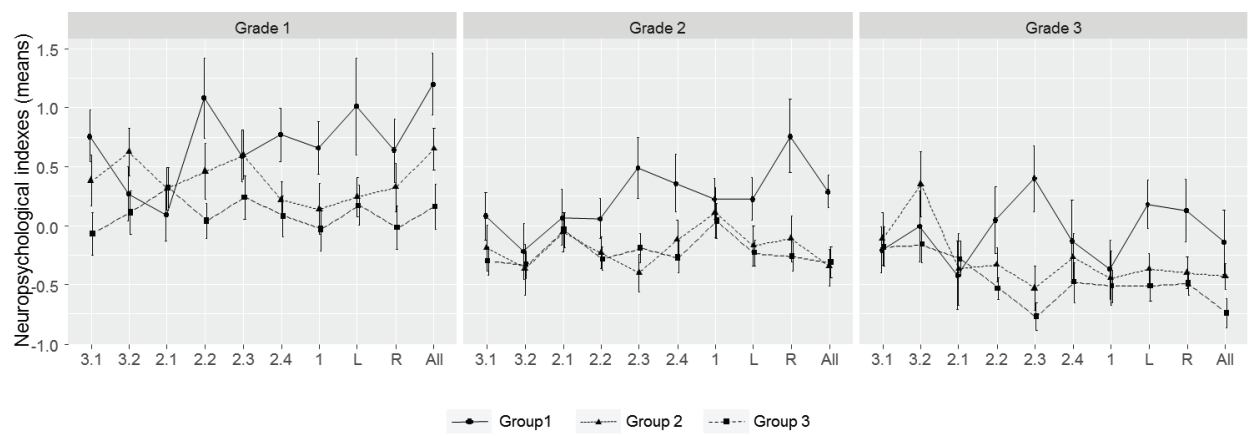

Figure 4. Neuropsychological indexes (means) for the three groups of children.

Note. $3.1=$ executive functions, $3.2=$ serial organization, $2.1=$ processing of kinesthetic information, 2.2 = processing of auditory information, 2.3 = processing of visual information, 2.4 = processing of visuospatial information, $\mathrm{L}=$ left hemisphere index, $\mathrm{R}=$ right hemisphere index, 1 = the first brain unit index, All = summary index.

Spearman correlation coefficients between the four neuropsychological indexes of interest (processing of auditory and visuospatial information, as well as left and right hemisphere functions) and understanding of GCs were also calculated for each of the three groups (the distribution was not normal for some indexes). Significant correlations were found in Group 1 (AR and processing of visuospatial information $\left[r_{s}=-0.29, p=.044\right], \mathrm{PD}$ and processing of auditory information $\left[r_{s}=-0.28, p=.048\right], \mathrm{PD}$ and left hemisphere functions $\left.\left[r_{s}=-0.3, p=.04\right]\right)$ and Group 3 (AD and left hemisphere functions $\left[r_{s}=-0.32, p<.0001\right]$, AR and left hemisphere functions $\left[r_{s}=-0.185, p=.045\right]$, PD and processing of visuospatial information $\left[r_{s}=-0.23, p=.014\right], \mathrm{PD}$ and left hemisphere functions $\left[r_{s}=-0.27\right.$, $p=.003]$, PR and right hemisphere functions $\left.\left[r_{s}=-0.2, p=.033\right]\right)$. Then, $p$-values were corrected for multiple comparisons $(p<.05 / 4$, i.e. $p<.0125)$, and only two correlations for Group 3 remained significant: between $\mathrm{AD}$ and left hemisphere functions $\left.r_{s}=-0.32, p<.0001\right)$, and between PD and left hemisphere functions $\left(r_{s}=-0.27, p=.003\right)$.

\section{Discussion}

Study of the understanding of active and passive GCs showed both common and different features in test performances of the three groups of children. All children were characterized by high productivity and the fastest correct responses to $\mathrm{AD}$, being the prototypical constructions with the most frequent word order and morphological aspects. This finding may be explained through holistic recognition 
(recognition by analogy) of $\mathrm{AD}$ constructions, which is accessible to children from the age of two (Dittmar et al., 2014).

The revealed differences allow us to suggest that children in Group 1 rely on the rule "The first noun is the agent". This is confirmed by the high productivity of their answers in $\mathrm{AD}$ and $\mathrm{PR}$ constructions, where the agent is in the first place. Evidence for this suggestion also includes the small percentage of correct responses $(43,50$, $43 \%$ in grades $1-3$, respectively) and the slowest response times (from 4,666 to $5,936 \mathrm{~ms}$ ) in unfamiliar PD constructions. Responses to AR require additional explanations: they are slightly better than random $(62,60$, and $67 \%$ in grades $1-3$, respectively) but quite fast (4,288 $\mathrm{ms}$, close to $4,264 \mathrm{~ms}$ for PR in the first grade). We hypothesize that AR constructions may also be recognized holistically, although to a lesser degree than $\mathrm{AD}$.

Group 2 in all grades demonstrated minimal differences in response time between $\mathrm{AD}$ and $\mathrm{AR}$ constructions, and the maximal difference in productivity and response time between $\mathrm{AD}$ and $\mathrm{PR}$ constructions. These findings may be explained through, firstly, holistic recognition of $\mathrm{AD}$ and $\mathrm{AR}$, and secondly, via a step-by-step acquisition of the rules of surface syntax. Rules of PR understanding are learned last; these constructions are rare and cannot be recognized as gestalts, and children cannot rely on word order in understanding them.

Children in Groups 1 and 2 are more rigid in using strategies; for understanding AR, PD, and PR constructions, they use distinct strategies. Children in Group 3 flexibly use different strategies.

It is most difficult to explain why Group 3 responds more slowly than the others in the first grade and much faster later, whereas Groups 1 and 2 demonstrate a significant increase in response times from the first to the third grade. Children of Group 3 have the best neuropsychological scores and are most successful at school. Acquisition of reading and writing skills has been found to improve the structuralfunctional organization of language and perception (Dehaene, Cohen, Morais, \& Kolinsky, 2015). These authors hypothesized that such a reconstruction may also influence syntactic processes. If they are right, it may explain the earlier reorganization and temporal imbalance of language processes in the most successful children (in first grade), which takes place later in less successful children (in second and third grades). This hypothesis requires further examination.

How may our data be combined with the above-mentioned facts regarding the development of GC understanding in children aged 3-5 years? The obtained results demonstrate that the strategy of reliance on word order is persistent in a significant part of 7- to 9-year-old children, which is an unexpected finding due to the data of 1985-1989 (Akhutina, 1989; Akhutina, Velichkovskiy, \& Kempe, 1988; Kempe, 1985). Can our results be explained using Karmiloff-Smith's RR model? This model allows for a coexistence of multiple representations of a singular knowledge: There are multiple levels at which the same knowledge is represented. For instance, specialists in aphasiology are very well familiar with the possibility of actualizing procedurally represented knowledge in patients' involuntary utterances (Jackson, 1884; Luria, 1970). Akhutina (1989) explains two other facts in the speech of patients with agrammatism, by the stability of procedural knowledge. Firstly, she points to the frequent usage of correct (but not regular) GC constructions, which are sometimes rejected by patients in accordance with the new knowledge reflected by them 
("Mal'chik myls'a-net! - myt's'a k mal'chik. Mama myl v mal'chik" / "The boy washed himself - no! - to wash to the boy. The mother washed in the boy"). Secondly, she notes the best performance on tests of grammaticality judgment compared to tests of the construction and understanding of GCs. This is interpreted through reliance on auditory-motor stereotypes that represent, in accordance with the ideas of N.A. Bernstein (1967), "a background technical level in the surface-syntactical design of an utterance" (Akhutina, 1989, p. 167). This can be considered as a procedural level in the RR model. Modern researchers of children's speech have described the discrepancy between understanding and constructing GCs, on the one hand, and syntactic priming tests, on the other, which also may be explained through representations of different levels (Huttenlocher, Vasilyeva, \& Shimpi, 2004).

Regarding the persistence of the rule "The first noun is the agent", we suggest that in children it may coexist with the rules of GC understanding of different levels: a procedural one (as in the case of high-frequency constructions, $\mathrm{AD}$, and to a lesser degree AR), and one that is more mature, close to an adult level (taking both inflections and word order into account, as in passive constructions). Different levels of representations may win in the competition for the rules in different children (compare to the Competition Model in MacWhinney \& Bates, 1989).

The stability of the word order rule we found may be linked to the agent advantage in event recognition: If the Agent is in the first place, that facilitates the interpretation of events (Cohn, Paczynski, \& Kutas, 2017; Hafri, Trueswell, \& Strickland, 2018). The retention of events in long-term memory might possibly also be associated with the Agent advantage, and this might explain the widespread overgeneralization of the word order rule in children between 3.5 and 4 years old, when access to episodic memory becomes available.

Finally, the last comment addresses the localization of syntactic processes. In our previous publications regarding children in the first and second grades (Akhutina et al., 2017a and 2017b), we wrote about the increasing role of the left hemisphere and involvement of both hemispheres in the strategy "The first noun is the agent". In our current work, we found that understanding AD and PD constructions correlates with the functioning of the left hemisphere in Group 3, the most successful group. These correlations remained significant after correction for multiple comparisons. Significant correlations in Group 1 were found between AR understanding and the index of visuospatial perception, as well as between PD understanding and the index of left hemisphere functions and auditory information processing; however, these correlations become nonsignificant after correction for multiple comparisons. We interpret these facts as a manifestation of the more diffuse nature of syntactic processes' representation in Group 1, as well as an increasing role of the left hemisphere in children of Group 3 being more successful in syntactic processes, which is consistent with the literature (Pakulak, \& Neville, 2010; Skeide \& Friederici, 2016).

\section{Conclusion}

1. Primary-school-age children demonstrate different strategies of GC understanding, relying either on word order ("The first noun is the agent"), or on the complex usage of both inflections and word order. 
2. Group 1 is the weakest in neuropsychological indexes and Group 3 is the strongest. The children of these groups differ in more or less diffuse activation of the brain: Group 3 demonstrates predominantly left-lateralized activation, whereas Group 1 is characterized by more diffuse activation.

3. We suggest the following possible interpretation of the fact that Group 3 is the slowest at first, becoming the fastest later, whereas the other two groups, conversely, become slower in the second grade: this may be linked to a restructuring of language mechanisms caused by acquiring literacy. Successful children of Group 3 acquire reading skills earlier, so this restructuring occurs earlier in them and later in the other two groups.

\section{Limitations}

We analyzed the results of independent samples in the first, second, and third grades, and therefore this study was not longitudinal. A longitudinal study must be carried out for more precise results.

\section{Acknowledgements}

The work is supported by the RFBR, Project № 16-06-01001.

\section{References}

Akhutina, T.V. (1979). Trudnosti ponimaniya grammaticheskikh konstrukciy u bol'nykh s afaziei [Difficulties of understanding grammatical constructions in aphasic patients]. Problemy afazii i vosstanovytel'nogo obucheniya (pp. 40-59). Moscow: Moscow University Press.

Akhutina, T.V. (1989). Porozhdenie rechi: Nejrolingvisticheskiy analiz sintaksisa [Language production: Neurolinguistic analysis of syntax]. Moscow: Moscow University Press.

Akhutina, T.V., Korneev, A.A., Matveeva, E.Yu., Romanova, A.A., Agris, A.P., Polonskaya, N.N., ....Kuzeva, O.V. (2016). Metody nejropsikhologicheskogo obsledovaniya detey 6-9 let [Neuropsychological assessment of 6-9-year-old children]. Moscow: V. Sekachev.

Akhutina, T.V., Korneev, A.A., Matveeva, E.Yu. (2017a). Dve strategii ponimaniya logiko-grammaticheskih konstrukciy u pervoclassnikov [Two strategies of understanding reversible sentences in primary-school pupils]. Voprosy psikholingvistiki, 31(1), 10-29.

Akhutina, T.V., Korneev, A.A., Matveeva, E.Yu. (2017b). Vozrastnaya dinamika ponimaniya logiko-grammaticheskikh konstrukcyi u mladshikh shkollikh s i ee mozgovye mekhanizmy [Age-related dynamics of understanding logical-grammatical constructions in primaryschool pupils and its brain mechanisms]. Special'noye obrazovaniye, 3, 15-31.

Akhutina, T.V., Velichkovskiy, B.M., \& Kempe, V. (1988). Semanticheskiy sintaksis i orientatsia na poryadok slov $\mathrm{v}$ ontogeneze [Semantic syntax and orientation on the word order in ontogeny]. Semantika $v$ rechevoi deyatelnosti (pp. 5-19). Moscow: Nauka.

Ambridge, B., Kidd, E., Rowland, C., \& Theakston, A. (2015). The ubiquity of frequency effects in first language acquisition. Journal of Child Language, 42(2), 239-273. https://doi. org/10.1017/S030500091400049X

Bates, E. (1976). Language and context: The acquisition of pragmatics. N.Y.: Academic Press.

Bates, E., Bretherton, I., \& Snyder, L. (1988). From first words to grammar. Individual differences and dissociable mechanisms. N.Y.: Cambridge University Press.

Bernstein, N. A. (1967). The co-ordination and regulation of movements. N.Y.: Pergamon Press. 
Bever, T. G. (1970). The cognitive basis for linguistic structures. In R. Hayes (Ed.), Cognition and language development (279-362). N.Y.: Wiley and Sons.

Bever, T. G., Mehler, J., \& Valian, V. (1968). Linguistic capacity of very young children. (Report No. AL001214). U.S. Department of Health, Education and Welfare. Office of Education.

Bozic, M., Tyler, L. K., Ives, D. T., Randall, B., \& Marslen-Wilson, W. D. (2010). Bihemispheric foundations for human speech comprehension. Proceedings of the National Academy of Sciences of the United States of America, 107(40), 17439-17444. https://doi.org/10.1073/ pnas. 1000531107

Buckle, L., Lieven, E., \& Theakston, A. L. (2017). The effects of animacy and syntax on priming: A developmental study. Frontiers in Psychology. 8, 2246. https://doi.org/10.3389/fpsyg.2017.02246

Cohn, N., Paczynski, M., \& Kutas, M. (2017). Not so secret agents: Event-related potentials to semantic roles in visual event comprehension. Brain and Cognition, 119, 1-9. https://doi. org/10.1016/j.bandc.2017.09.001

Dąbrowska, E. (2012). Different speakers, different grammars: Individual differences in native language attainment. Linguistic Approaches to Bilingualism, 2(3), 219-253. https://doi. org/10.1075/lab.2.3.01dab

Dehaene, S., Cohen, L., Morais, J., \& Kolinsky, R. (2015). Illiterate to literate: Behavioural and cerebral changes induced by reading acquisition. Nature Reviews Neuroscience, 16(4), 234244. https://doi.org/10.1038/nrn3924

Dittmar, M., Abbot-Smith, K., Lieven, E., \& Tomasello, M. (2008). German children's comprehension of word order and case marking in causative sentences. Child Development, 79(4), 1152-1167. https://doi.org/10.1111/j.1467-8624.2008.01181.x

Dittmar, M., Abbot-Smith, K., Lieven, E., \& Tomasello, M. (2014). Familiar verbs are not always easier than novel verbs: How German pre-school children comprehend active and passive sentences. Cognitive Science, 38(1), 128-151. https://doi.org/10.1111/cogs.12066

Dobrova, G.R. (2009). O variativnosti rechevogo ontogeneza: referencial'naya i expressivnaya strategii osvoeniya yazika. [Variability of language ontogeny: referential and expressive strategies of language acquisition]. Voprosy psikholingvistiki, 9, 53-69.

Dragoy, O.V., Bergelson, M.B., Iskra, E.V., Laurinavichute, A.K., Mannova, E.M., Skvortsov, A.I., \& Statnikov, A.I. (2015). Sensomotornye stereotipy v yazike: dannye patologii rechi [Sensomotor stereotypes in language: data from language pathology]. Yazik i mysl': sovremennaya kognitivnaya lingvistika (pp. 697-720). Moscow: Yaziki slavianskoy kulturi.

Hafri, A., Trueswell, J. C., \& Strickland, B. (2018). Encoding of event roles from visual scenes is rapid, spontaneous, and interacts with higher-level visual processing. Cognition, 175, 36-52. https://doi.org/10.1016/j.cognition.2018.02.011

Hakuta, K. (1982). Interaction between particles and word order in the comprehension and production of simple sentences in Japanese children. Developmental Psychology, 18(1), 62-76. https://doi.org/10.1037/0012-1649.18.1.62

Huttenlocher, J., Vasilyeva, M., \& Shimpi, P. (2004). Syntactic priming in young children. Journal of Memory and Language, 50(2), 182-195. https://doi.org/10.1016/j.jml.2003.09.003

Just, M. A., \& Carpenter, P. A. (1992). A capacity theory of comprehension: Individual differences in working memory. Psychological Review, 99(1), 122-149. https://doi.org/10.1037/0033295X.99.1.122

Jackson, J. H. (1884). Evolution and dissolution of the nervous system. Lancet, 535-649.

Karmiloff-Smith, A. (1995). Beyond modularity: A developmental perspective on cognitive science. Cambridge: MIT Press.

Kempe, V. (1985). Orientatsiya na poryadok slov v ponimanii predlozheniy u russkikh i nemetskikh detei: diplomnaya rabota [Orientation to word order in understanding sentences 
by Russian and German children: diploma thesis]. Moscow: Lomonosov Moscow State University.

Korneev, A.A. \& Akhutina, T.V. (2016). Podschet nejropsykhologicheskikh indeksov [Calculation of neuropsychological indexes]. In T.V. Akhutina (Ed.), Metody nejropsikhologicheskogo obsledovaniya detei 6-9 let [Methods of neuropsychological study of 6- to 9-year-old children] (pp. 171-186). Moscow: V. Sekachev.

Luria,A.R.(1970).Traumaticaphasia. TheHague:Mouton.https://doi.org/10.1515/9783110816297 Luria, A.R. (1973). The working brain. N.Y.: Basic Books.

MacWhinney, B. \& Bates, E (1989) The crosslinguistic study of sentence processing. N.Y.: Cambridge University Press.

MacWhinney, B., Pléh, C., \& Bates, E. (1985). The development of sentence interpretation in Hungarian. Cognitive Psychology, 17(2), 178-209. https://doi.org/10.1016/0010-0285(85)90007-6

Nelson, K. (1973). Structure and strategy in learning to talk. Monographs of the Society for Research in Child Development. 38(1/2), 1-135. https://doi.org/10.2307/1165788

Pakulak, E., \& Neville, H. J. (2010). Proficiency differences in syntactic processing of monolingual native speakers indexed by event-related potentials. Journal of Cognitive Neuroscience. 22(12), 2728-2744. https://doi.org/10.1162/jocn.2009.21393

Pléh, C. (1981). The role of word order in the sentence interpretation of Hungarian children. Folia Linguistica, 15(3-4), 331-344. https://doi.org/10.1515/flin.1981.15.3-4.331

Prat, C. S., \& Just, M. A. (2011). Exploring the neural dynamics underpinning individual differences in sentence comprehension. Cerebral Cortex. 21(8), 1747-1760 https://doi. org/10.1093/cercor/bhq241

Skeide, M. A., \& Friederici, A. D. (2016). The ontogeny of the cortical language network. Nature Reviews Neuroscience, 17(5), 323-332. https://doi.org/10.1038/nrn.2016.23

Slobin, D. I. (1966). Grammatical transformations and sentence comprehension in childhood and adulthood. Journal of Verbal Learning and Verbal Behavior, 5(3), 219-227. https://doi. org/10.1016/S0022-5371(66)80023-3

Slobin, D. I., \& Bever, T. G. (1982). Children use canonical sentence schemas: A crosslinguistic study of word order and inflections. Cognition, 12(3), 229-265. https://doi.org/10.1016/00100277(82)90033-6

Shore, C.M. (1995). Individual differences in language development. London: Sage Production. https://doi.org/10.4135/9781483327150

Statnikov, A.I. (2015). Sindromniy analiz trudnostey ovladeniya ponimaniyem logiko-grammaticheskikh konstruktskiy [Syndrome analysis in understanding logical-grammatical constructions]. Natsionalniy psikhologicheskiy zhurnal, 2(18), 62-70.

Statnikov, A. I., \& Akhutina, T. V. (2013). Logical-grammatical constructions comprehension and serial organization of speech: Finding the link using computer-based tests. Procedia - Social and Behavioral Sciences, 86, 518-523. https://doi.org/10.1016/j.sbspro.2013.08.607

Thothathiri, M., Kimberg, D. Y., \& Schwartz, M. F. (2012). The neural basis of reversible sentence comprehension: Evidence from voxel-based lesion symptom mapping in aphasia. Journal of Cognitive Neuroscience, 24(1), 212-222. https://doi.org/10.1162/jocn_a_00118

Tomasello, M. (2009). The usage-based theory of language acquisition. In: Cambridge Handbook of Child Language, (pp. 69-87). N.Y.: Cambridge University Press. https://doi.org/10.1017/ CBO9780511576164.005

Wright, P., Stamatakis, E. A., \& Tyler, L. K. (2012). Differentiating hemispheric contributions to syntax and semantics in patients with left-hemisphere lesions. Journal of Neuroscience. 32(24), 8149-8157. https://doi.org/10.1523/JNEUROSCI.0485-12.2012 
Yeatman, J. D., Ben-Shachar, M., Glover, G. H., \& Feldman, H. M. (2010). Individual differences in auditory sentence comprehension in children: An exploratory event-related functional magnetic resonance imaging investigation. Brain and Language, 114(2), 72-79. https://doi. org/10.1016/j.bandl.2009.11.006

Original manuscript received October 8, 2018 Revised manuscript accepted January 10, 2019 First published online February 15, 2019

To cite this article: Akhutina, T.V., Panikratova, Y.R., Korneev, A.A., Matveeva, E.Yu. \& Vlasova, R.M. (2019). Understanding of active and passive constructions in 7- to 10-year-old Russian-speaking children: Reliance on inflections or word order. Psychology in Russia: State of the Art, 12(1), 3-20. DOI: $10.11621 /$ pir.2019.0101

\section{Appendix}

Table 1A

Productivity and time of correct responses (means) for the three groups of children.

\begin{tabular}{|c|c|c|c|c|c|c|c|}
\hline \multirow{2}{*}{$\begin{array}{c}\text { Grammatical } \\
\text { construction type }\end{array}$} & \multirow{2}{*}{ Grade } & \multicolumn{3}{|c|}{$\begin{array}{c}\text { Productivity } \\
\text { (\% correct responses) }\end{array}$} & \multicolumn{3}{|c|}{ Time of correct responses (ms) } \\
\hline & & Group 1 & Group 2 & Group 3 & Group 1 & Group 2 & Group 3 \\
\hline \multirow{3}{*}{$\mathrm{AD}$} & 1 & 84 & 87 & 87 & 3,980 & 4,025 & 4,079 \\
\hline & 2 & 95 & 84 & 90 & 4,002 & 4,358 & 3,967 \\
\hline & 3 & 85 & 86 & 89 & 3,757 & 3,872 & 3,700 \\
\hline \multirow{3}{*}{$\mathrm{AR}$} & 1 & 62 & 77 & 79 & 4,288 & 4,476 & 4,441 \\
\hline & 2 & 60 & 75 & 83 & 5,728 & 4,977 & 4,233 \\
\hline & 3 & 67 & 80 & 79 & 4,880 & 4,149 & 4,144 \\
\hline \multirow{3}{*}{$\mathrm{PD}$} & 1 & 43 & 78 & 87 & 4,665 & 4,792 & 4,915 \\
\hline & 2 & 50 & 77 & 90 & 5,936 & 5,046 & 4,458 \\
\hline & 3 & 43 & 91 & 90 & 5,934 & 4,251 & 3,998 \\
\hline \multirow{3}{*}{ PR } & 1 & 75 & 54 & 89 & 4,264 & 5,283 & 4,628 \\
\hline & 2 & 71 & 47 & 90 & 5,782 & 5,482 & 4,459 \\
\hline & 3 & 72 & 57 & 89 & 5,180 & 4,925 & 4,414 \\
\hline
\end{tabular}


Table 2A

Neuropsychological indexes (means) for the three groups of children

\begin{tabular}{|c|c|c|c|c|}
\hline Neuropsychological index & Grade & Group 1 & Group 2 & Group 3 \\
\hline \multirow{3}{*}{ Executive functions (3.1) } & 1 & 0.76 & 0.38 & -0.07 \\
\hline & 2 & 0.08 & -0.19 & -0.3 \\
\hline & 3 & -0.21 & -0.11 & -0.18 \\
\hline \multirow{3}{*}{ Serial organization (3.2) } & 1 & 0.27 & 0.62 & 0.11 \\
\hline & 2 & -0.22 & -0.37 & -0.33 \\
\hline & 3 & -0.005 & 0.35 & -0.16 \\
\hline \multirow{3}{*}{ Processing of kinesthetic information (2.1) } & 1 & 0.09 & 0.31 & 0.32 \\
\hline & 2 & 0.07 & -0.06 & -0.04 \\
\hline & 3 & -0.42 & -0.37 & -0.28 \\
\hline \multirow{3}{*}{ Processing of auditory information (2.2) } & 1 & 1.08 & 0.46 & 0.04 \\
\hline & 2 & 0.06 & -0.23 & -0.28 \\
\hline & 3 & 0.05 & -0.33 & -0.53 \\
\hline \multirow{3}{*}{ Processing of visual information (2.3) } & 1 & 0.59 & 0.6 & 0.24 \\
\hline & 2 & 0.49 & -0.4 & -0.19 \\
\hline & 3 & 0.4 & -0.53 & -0.77 \\
\hline \multirow{3}{*}{ Processing of visuospatial information (2.4) } & 1 & 0.77 & 0.22 & 0.08 \\
\hline & 2 & 0.36 & -0.12 & -0.27 \\
\hline & 3 & -0.13 & -0.27 & -0.48 \\
\hline \multirow{3}{*}{ Left hemisphere } & 1 & 1.01 & 0.24 & 0.17 \\
\hline & 2 & 0.23 & -0.17 & -0.23 \\
\hline & 3 & 0.18 & -0.37 & -0.51 \\
\hline \multirow{3}{*}{ Right hemisphere } & 1 & 0.64 & 0.32 & -0.02 \\
\hline & 2 & 0.76 & -0.11 & -0.26 \\
\hline & 3 & 0.13 & -0.4 & -0.49 \\
\hline \multirow{3}{*}{ Regulation of activation (the first brain unit) } & 1 & 0.66 & 0.14 & -0.03 \\
\hline & 2 & 0.23 & 0.11 & 0.04 \\
\hline & 3 & -0.37 & -0.45 & -0.51 \\
\hline \multirow{3}{*}{ Summary index } & 1 & 1.2 & 0.65 & 0.16 \\
\hline & 2 & 0.29 & -0.35 & -0.31 \\
\hline & 3 & -0.14 & -0.43 & -0.74 \\
\hline
\end{tabular}

